Working Paper 9609

\title{
ON THE POLITICAL ECONOMY OF INCOME REDISTRIBUTION AND CRIME
}

by Ayşe İmrohoroğlu, Antonio Merlo, and Peter Rupert

Ayşe İmrohoroğlu is an associate professor of economics at the University of Southern California, Antonio Merlo is an assistant professor of economics at the University of Minnesota and a consultant at the Federal Reserve Bank of Minneapolis, and Peter Rupert is an economist at the Federal Reserve Bank of Cleveland. For their useful comments, the authors thank V.V. Chari, Larry Christiano, J ohn Geweke, Mike Keane, Finn Kydland, Lee Ohanian, Richard Rogerson, Neil Wallace, and seminar and conference participants at many institutions. Dayong Jin and Kristin Roberts provided excellent research assistance. Antonio Merlo acknowledges the financial support of the National Science Foundation.

Working papers of the Federal Reserve Bank of Cleveland are preliminary materials circulated to stimulate discussion and critical comment. The views stated herein are those of the authors and not necessarily those of the Federal Reserve Bank of Cleveland or of the Board of Governors of the Federal Reserve System.

Working papers are now available electronically through the Cleveland Fed's home page on the World Wide Web: http: //www.clev.frb. org.

November 1996 


\begin{abstract}
In this paper, we consider a general equilibrium model in which heterogeneous agents specialize either in legitimate market activities or in criminal activities, and majority rule determines the share of income redistributed and the expenditures devoted to the apprehension of criminals. We calibrate our model to the U.S. economy in 1990, and conduct simulation exercises to evaluate the effectiveness of expenditures on police protection and income redistribution at reducing crime. We find that while expenditures on police protection reduce crime, it is possible for the crime rate to increase with redistribution. We also show that economies which adopt relatively more generous redistribution policies may have either higher or lower crime rates than economies with relatively less generous redistribution policies, depending on the characteristics of their wage distribution and on the efficiency of their apprehension technology.
\end{abstract}




\section{Introduction}

As crime has been escalating over the last two decades to become one of the most important public policy issues in the United States, so too has the debate over alternative crime-control policies. Becker's (1968) seminal work on the economic analysis of criminal behavior represents the starting point for analyzing society's choice of crime-control policies in the context of an economic model. Becker proposes a framework where an individual rationally decides whether to engage in criminal activities by comparing the expected returns to crime with the returns to legitimate market opportunities. Hence, one way of making crime less attractive is to increase the certainty and severity of punishment, which reduces the expected returns to crime. Another way of making crime less attractive, however, is to increase the returns to legitimate alternatives to crime, which increases the opportunity cost of crime. In particular, welfare programs and, more generally, redistribution programs that collect taxes from individuals with high market incomes and give subsidies to those with low market incomes may be effective policy instruments for reducing crime. ${ }^{1}$

To date, most of the theoretical literature on crime has focused on the role of deterrence in reducing crime. Becker (1968), Harris (1970), Stigler (1970), Ehrlich(1973), and Polinsky and Shavell (1984), among others, characterize opt imal penalties and enforcement levels in the context of partial equilibrium models where the normative criterion is to minimize a given function that measures the social loss resulting from crime. Ehrlich (1981) and Furlong (1987) address these normative issues in the context of a general equilibrium framework that explicitly models the interactions among the participants in the market for crime. Benoit and Osborne (1995) take a positive approach to analyze societ y's choice of a crime-control policy and explicitly consider programs that involve redistribut-

1 See Ehrlich (1996) for a recent survey of the debate over the relative efficacy and desirability of alternative crime-control policies. 
ing income from rich to poor as a possible way to reduce crime. In their model, however, expenditures on enforcement and the redistribution of income are combined into a single policy instrument that is assumed to reduce crime at a direct resource cost. Sala-i-Martin (1992) explores the relationship between income redistribution and growth in the context of a partial equilibrium model of optimal criminal behavior where redistributional transfers act as a crime-control device. He finds that transfers are an effective way to reduce crime because they unambiguously reduce the incentives to commit crimes.

Empirical evidence both at the aggregate and the individual level indicates that there exists a strong inverse relationship between both the probability of apprehension and the severity of punishment and levels of criminal activity. ${ }^{2}$ In addition, there exists some evidence that individuals with lower market incomes are more likely to engage in criminal activities and that property-related crime rates are positively correlated with the unemployment rate and income inequality. ${ }^{3}$ However, we are aware of no systematic attempt to assess empirically the impact of welfare transfers and income redistribution programs on crime, and the evidence that emerges from social experiments implemented to assess the response of ex-prisoners to such programs is mixed. ${ }^{4}$ Intrinsic data limitations, together with the methodological problems that arise in the design of social experiments as well as in the specification and estimation of reduced-form models of criminal behavior,

${ }^{2}$ See, e.g., Ehrlich (1973); Wolpin (1978); Witte (1980); and Tauchen, Witte, a n d Griesinger (1994).

${ }^{3}$ These findings, however, appear to be highly sensitive to the choice of data and of the econometric specification (see, e.g., the survey by Freeman [1983]).

${ }^{4}$ For instance, while the results of the 1971 Baltimore Living Insurance For Ex-Prisoners (LIFE) experiment showed that ex-prisoners receiving subsidies were less likely to be rearrested for property-related crimes than those who did not receive subsidies, the results of the Transitional Aid Research Project(TARP) experimental program that was implemented in Georgia and Texas in 1976 indicated that the work disincentives of unemploy ment insurance benefits given to ex-prisoners reduced their employment and increased their involvement in property-related crimes. Both the experiments and their results are discussed in detail by Rossi, Berk, and Lenihan [1980]. 
are clearly responsible for the lack of compelling evidence concerning the relationship bet ween economic conditions and crime (Ehrlich [1996]), which in turn kindles the skepticism of policy makers toward the economic approach to the study of criminal behavior (Dilulio [1996]). Given the inconclusiveness of empirical evidence, substantial insight can be gained from a carefully designed simulation exercise.

In this paper, we build a general equilibrium model to evaluate the relative desirability of alternative crime-control policies. The policy instruments we consider are police protection and income redistribution. We focus on the effects that expenditures on police protection and income redistribution have on crime, and we explicitly model the political process that determines the expenditure levels chosen by society.

We consider an economy populated by a large number of het erogeneous agents who differ with respect to their labor market productivity. Each agent chooses to specialize either in legitimate market activities or in illegitimate activities. Taxes on labor income are used to finance a redistribute ion scheme and to operate an apprehension technology. The share of income redistributed and the expenditures devoted to the apprehension of criminals are determined by majority rule. Voters rationally anticipate the disincentive effects of taxes on the labor-leisure choices of the agents in the economy. Voters also perceive that taxes affect the participation decision in legitimate vs. illegitimate activities, partly through their impact on the probability y of criminals' apprehension.

We calibrate our model to the U.S. economy in 1990, and by first abstracting from the political process, we examine the impact of government subsidies and police expenditures on the crime rate under different specifications of the wage distribution and the apprehension technology. We find that, if the government is not able to distinguish between the recipients of transfer payments, it is possible for the crime rate to increase with redistri- 
bution. The intuition for this result derives primarily from the fact that if the government cannot prevent criminals from receiving transfers unless they are convicted of a crime, then higher subsidies do not necessarily increase the opportunist y cost of crime, while the tax increase required to finance the higher subsidies reduces the returns to legitimate activities. The crime rate, however, is lower the more efficient the apprehension technology and the higher the level of expenditures devoted to the apprehension of criminals. Thus, the efficiency of the apprehension technology and the level at which it is operated, together wit $\mathrm{h}$ the extent to which government agencies can monitor individual behavior, are very important factors in determining the effectiveness of redistribution policies for reducing crime.

In an economy like the United States, where the distribution of wages is significantly skewed toward high wage rates (i.e., the median of the wage distribution is significantly below the mean), we would expect majority voting to induce high levels of redistribution. However, the perverse effect of redistribution on the crime rate may limit the level of transfers in a political-economic equilibrium. We find that, for a given distribution of wages, the extent to which the possible increase in the crime rate induced by the higher subsidies constrains the majority's choice of an income redistribution policy depends on the efficiency of the apprehension technology.Ceteris paribus, the more efficient the apprehension technology, the higher the level of transfers in a political-economic equilibrium.

Finally, we find that the crime rate in a political-economic equilibrium decreases with the mean of the wage distribution while it increases with wage inequality. We also show that economies which adopt relatively more generous realist ribut ion policies may have either higher or lower crime rates than economies with relatively less generous redistribution policies, depending on the characteristics of their wage distribution and on the efficiency 
of their apprehension technology.

The remainder of the paper is organized as follows. In Section 2 we describe the model. In Section 3 we present the data and discuss the calibration of the model. Section 4 contains the results. We conclude in Section 5 with comments and directions for future research.

\section{Structure of the Economy}

The economy is populated by a large number of ex ante heterogeneous agents who differ with respect to their productivity y in the labor market, $w \in(0,+\infty)$. We normalize the mass of agents in the economy to one and let $F(\cdot)$ denote the cumulative distribution of productivity in the population. We assume that $F(\cdot)$ is a log-normal distribution; i.e., $\ln (w)$ has a normal distribution with mean $w$ and standard deviation $\sigma_{w}$.

The utility function for consumption, $c$, and leisure, $l$, is assumed to have the following form:

$$
U(c, l)=(1-a) \ln (c)+a \ln (l),
$$

where $a \in(0,1)$ is the share of leisure in the utility function. Each agent is endowed with $T$ units of time. We assume that individuals choose careers in the sense that they specialize in either legitimate or illegitimate activities.

Agents who choose to specialize in legitimate market activities allocate their time endowment bet ween work and leisure. An individual with productivity $w$ who works $n(w)$ hours earns pre-tax income $y(w)=w n(w)$. Individual productivity $\mathrm{y}$ is not observable, so taxes are levied against earned income. An individual with labor income $y$ pays taxes $Z_{-}{ }^{\prime} \mid(y)=t_{1} y$ and $T_{2}(y)=t_{2} y, t_{1}, t_{2} \in[0,1), t_{1}+t_{2}<1$, and receives a lump-sum subsidy

s. Tax payments $T_{1}(y)$ are used to operate a t ethnology that apprehends criminals, and 
tax payments $T_{2}(y)$ finance a redistribution scheme that pays a per capita subsidy $s .{ }^{5}$ In addition, workers may have to pay a lump-sum $\operatorname{tax} \tau$ that generates revenues to be used for other purposes.

We assume that the technology available to apprehend criminals is in the form of security cameras that can be operated at a direct resource cost to monitor the interactions among the agents in the economy. Each employed agent is faced with the possibility of being victimized by a criminal. In fact, with probability $\pi_{v}$, equal to the fraction of criminals in the population (which is endogenous to our model), a worker will be the victim of a crime. With probability $\pi_{a}$, however, a camera will monitor the event leading to the immediate apprehension, of the criminal and to no pecuniary loss to the victim, while with probability $1-\pi_{a}$ the crime will not be monitored by a camera, in which case the victim will lose a fraction $\alpha$ of his after-tax income to the criminal, who will not be apprehended. We assume that

$$
\pi_{a}= \begin{cases}0, & \text { for } G \leq 1 \\ 1-G^{-\gamma}, & \text { for } G>1\end{cases}
$$

where $\mathrm{G}$ is the level of public expenditures devoted to the apprehension of criminals and $\gamma \in(0,1)$ is a parameter that measures the efficiency of the apprehension technology. ${ }^{6}$

An agent with labor productivity $w$ who decides to specialize in legitimate activities takes the policy parameters $t_{1}, t_{2}, G, s$, and $\tau$ and the behavior of all the agents in the

${ }^{5}$ We follow a large literature in modeling linear income taxes to finance redistribution. The conditions for optimal marginal tax rates under linear income taxes are studied by, among others, Sheshinski (1972), Mirrlees (1976), Stern (1976), and Hellwig (1986). Romer (1975), Roberts (1977), Meltzer and Richard (1981), and Aiyagari and Peled (1995) study models where linear income tax schedules are chosen by majority voting.

${ }^{6}$ There is no consensus in the literature on what is the most appropriate functional form to describe the apprehension technology, and empirical work to date has failed to provide compelling evidence in favor of any particular specification (see, e.g., the survey by Pyle (1983)). The functional form we use has the properties of being increasing and concave in the level of expenditures (for expenditures greater than $\$ 1$ ), and it is characterized by only one parameter. 
economy as given and chooses his labor supply, $n(w)$, to solve

$$
\max E[U(c(w), T-n(w))]
$$

subject to

$$
c(w)= \begin{cases}(1-\alpha)\left[\left(1-t_{1}-t_{2}\right) w n(w)+s-\tau\right], & \text { with prob. } \pi_{v}\left(1-\pi_{a}\right), \text { if } n(w)>0, \\ \left.1-t_{1}-t_{2}\right) w n(w)+s-\tau, & \text { with prob. } 1-\pi_{v}\left(1-\pi_{a}\right), \text { if } n(w)>0, \\ s, & \text { if } n(w)=0 .\end{cases}
$$

Solving this maximization yields the optimal labor choice

$$
n^{*}(w)= \begin{cases}\frac{T(1-a)\left(1-t_{1}-t_{2}\right) w-a s+a \tau}{\left(1-t_{1}-t_{2}\right) w}, & \text { if } w>w_{u}\left(t_{1}, t_{2}, G, s, \tau\right) \\ 0, & \text { if } w \leq w_{u}\left(t_{1}, t_{2}, G, s, \tau\right)\end{cases}
$$

where $w_{u}($.$) is the productivity y level below which agents who specialize in legitimate ac-$ tivities choose not to work and instead to subsist on welfare payments.

Agents who choose to engage in the illegal sector of the economy spend a constant fraction of their time trying to steal from other agents. We assume that a criminal can victimize at most one agent, who has to be a worker, and we normalize the labor input required to commit a crime to be zero. With probability $\pi_{h}$, equal to the fraction of workers in the economy (which is endogenous to our model), a criminal will hit a victim. In this case, with probability $1-\pi_{a}$ the criminal will be successful in stealing a fraction $\alpha$ of the victim's after-tax income, while with probability $\pi_{a}$ the criminal will be apprehended. With probability $1-\pi_{h}$, an agent who chooses to specialize in illegal activities will not find a victim and hence will not commit any crime. ${ }^{7}$

In general, agents who engage in criminal activities would not be eligible for government subsidies. However, in practice it may be difficult to distinguish between agents

${ }^{7}$ This specification would arise, for example, in a physical environment where production takes place in a single location, a factory, that could accommodate all the agents in the economy, and criminals try to steal from workers as they exit the factory, but do not necessarily meet a potential victim. In section 4.3 , we consider an alternative specification of the physical environment in which criminals and non-criminals interact. 
who are engaged in different activities, and only convicted criminals can effectively be excluded from government subsidies. We assume that an agent who commits a crime receives the subsidy $s$ with (exogenous) probability $\pi_{s}$ and loses the subsidy if he is apprehended of a crime. The probability $\pi_{s}$ can be interpreted as a measure of the ability of social workers to monitor the behavior of the recipients of transfer payments and to deny government subsidies to individuals who engage in illegal activities regardless of whether they are convicted of a crime. Although we believe that in reality government agencies cannot discriminate between criminals who are not caught committing a crime and non-criminals (i.e., $\pi_{s}=1$ ), we are interested in evaluating the potential effects on crime of a technology that would only prevent criminals from receiving subsidies without necessarily leading to their apprehension.

The budget constraint of an agent who specializes in illegal activities is given by

$$
c= \begin{cases}\alpha\left[\left(1-t_{1}-t_{2}\right) \tilde{y}+s-\tau\right]+s, & \text { with prob. } \pi_{h}\left(1-\pi_{a}\right) \pi_{s} f(\tilde{y}), \\ \alpha\left[\left(1-t_{1}-t_{2}\right) \tilde{y}+s-\tau\right], & \text { with prob. } \pi_{h}\left(1-\pi_{a}\right)\left(1-\pi_{s}\right) f(\tilde{y}), \\ c_{\min }, & \text { with prob. } \pi_{h} \pi_{a}, \\ s, & \text { with prob. }\left(1-\pi_{h}\right),\end{cases}
$$

where $\tilde{y}$ denotes pre-t ax income of a worker in the economy with density $f(\cdot)$, and $c_{\min }$ is an exogenously specified subsistence level of consumption. ${ }^{8}$

Given tax rates $t_{1}$ and $t_{2}$, lump-sum tax $\tau$, expenditures $G$, and subsidy s, and taking the behavior of the other agents in the economy as given, each agent chooses to specialize in legitimate or illegitimate activities by solving the following maximization problem:

$$
V\left(t_{1}, t_{2}, G, s, \tau ; w\right)=\max \left\{V_{l}\left(t_{1}, t_{2}, G, s, \tau ; w\right), V_{c}\left(t_{1}, t_{2}, G, s, \tau ; w\right)\right\}
$$

8 The extent of punishment is not explicitly modeled here, and we simply assume that apprehended criminals are held to a fixed subsistence level of consumption. Papers by Becker (1968), Harris (1970), Stigler (1970), Ehrlich (1973), and Polinsky and Shavell (1984) deal with this issue explicitly. In particular, they show that the severity of punishment is limited by the fact that innocent people are sometimes convicted or that a social gain may accompany the commission of an offense. 
where $V(\cdot ; w)$ is agent $w$ 's indirect expected utility. The indirect expected utility of agent $w$ if he engages in legitimate activities is given by

$$
V_{l}\left(t_{1}, t_{2}, G, s, \tau ; w\right)=\left\{\begin{array}{l}
V_{e}\left(t_{1}, t_{2}, G, s, \tau ; w\right), \text { if } w>w_{u}\left(t_{1}, t_{2}, G, s, \tau\right) \\
V_{u}\left(t_{1}, t_{2}, G, s, \tau ; u\right), \text { if } w \leq w_{u}\left(t_{1}, t_{2}, G, s, \tau\right)
\end{array}\right.
$$

where $e$ and $u$ denote employed and unemployed, respectively),

$$
\begin{aligned}
V_{e}\left(t_{1} t_{2}, G, s, \tau ; w\right)= & \pi_{v}\left(1-\pi_{a}\right) U\left((1-\alpha)\left[\left(1-t_{1}-t_{2}\right) w n^{*}(w)+s-\tau\right], T-n^{*}(w)\right) \\
& +\left(1-\pi_{v}\left(1-\pi_{a}\right)\right) U\left(\left(1-t_{1}-t_{2}\right) w n^{*}(w)+s-\tau, T-n^{*}(w)\right),
\end{aligned}
$$

and

$$
V_{u}\left(t_{1}, t_{2}, G, s, \tau ; w\right)=U(s, T)
$$

The indirect expected utility of agent $w$ if he engages in the illegal sector of the economy is given by ${ }^{9}$

$$
\begin{aligned}
V_{c}\left(t_{1}, t_{2}, G, s, \tau ; w\right)= & \pi_{h}\left(1-\pi_{a}\right) \pi_{s} E\left[U\left(\alpha\left[\left(1-t_{1}-t_{2}\right) \tilde{y}+s-\tau\right]+s, T\right)\right] \\
& +\pi_{h}\left(1-\pi_{a}\right)\left(1-\pi_{s}\right) E\left[U\left(\alpha\left[\left(1-t_{1}-t_{2}\right) \tilde{y}+s-\tau\right], T\right)\right] \\
& +\pi_{h} \pi_{a} U\left(c_{\min }, T\right)+\left(1-\pi_{h}\right) U(s, T) .
\end{aligned}
$$

It is straightforward to verify that $V_{e}(\cdot ; w)$ is increasing in $w$, while both $V_{u}(\cdot ; w)$ and $V_{c}(\cdot ; w)$ are independent of $\mathrm{w}$. Therefore, with respect to the agents' career choices there are only two possible equilibrium configurate ions, depending on whether $V_{c}(\cdot)>V_{u}(\cdot)$ or vice versa. If $V_{c}(\cdot)<V_{u}(\cdot)$, then crime does not pay (i.e., for any $w$, an individual is better off by not engaging in illegal activities). In this case, the aggregate level of criminal activity in the economy is zero, and all the agents with productivity below $w_{u}\left(t_{1}, t_{2}, G, s, \tau\right)$ are unemployed and subsist on welfare payments. If $V_{c}(\cdot)>V_{u}(\cdot)$, there exists a threshold

${ }^{9}$ We assume that criminals get the full amount of leisure whether or not they are apprehended. We choose this simplification because the measurement of the amount of leisure spent by convicted criminals is very unclear, and variations in the severity of punishment can be captured by varying $c_{\min }$. 
$w_{c}\left(t_{1}, t_{2}, G, s, \tau\right)>w_{u}\left(t_{1}, t_{2}, G, s, \tau\right)$ such that all the agents with productivity below $w_{c}(\cdot)$ specialize in illegal activities, while all the agents with productivity greater than or equal to $w_{c}(\cdot)$ are employed, and the only "unemployed" agents in the economy are the ones who choose to specialize in criminal activities but do not get the chance of committing any crime. (In the case where $V_{c}(")=V_{u}(\cdot)$, we assume that agents choose not to specialize in illegal activities.)

In an economy where the level of criminal activity is positive, the productivity threshold $w_{c}\left(t_{1}, t_{2}, G, s, \tau\right)$ is the solution to the following equation:

$$
V_{e}\left(t_{1}, t_{2}, G, s, \tau ; w_{c}\right)=V_{c}\left(t_{1}, t_{2}, G, s, \tau ; w_{c}\right)
$$

where

$$
\begin{gathered}
\pi_{h}=1-F\left(w_{c}\right), \\
\pi_{v}=F\left(w_{c}\right),
\end{gathered}
$$

and

$$
E[U(\cdot, \cdot)]=\int_{u w_{c}}^{+\infty} U\left(\alpha\left[\left(1-t_{1}-t_{2}\right) w n^{*}(w)+s-\tau\right]+s, T\right) d F(w)
$$

A competitive equilibrium for a given set of policy arrangements $t_{1}, t_{2}, G, \mathrm{~s}$, and $\tau$, and a distribution function $F(\cdot)$, consists of a productivity y threshold $w_{j}$, where $j=c$ or $u$, and a set of decision rules for consumption, and the number of hours worked by each worker, such that

(i) The goods market clears:

$$
\int_{w_{j}}^{+\infty} w n^{*}(w) d F(w)=\int_{O}^{+\infty} c(w) d F(w)+G
$$

(ii) Given the policy arrangements, the agents' decision rules solve (6) and (4). 
(iii) The following government budget constraints are satisfied:

$$
G=t_{1} \int_{w_{j}}^{+\infty} w n^{*}(w) d F(w)
$$

and, in an economy with crime,

$$
s\left[1-\pi_{a} \pi_{h} F\left(w_{c}\right)-\left(1-\pi_{s}\right) F\left(w_{c}\right)\right]=t_{2} \int_{w_{c}}^{+\infty} w n^{*}(w) d F(w),
$$

and $^{10}$

$$
c_{\min } \pi_{a} \pi_{h} F\left(w_{c}\right)=\tau\left[1-F\left(w_{c}\right)\right],
$$

while, in an economy with no crime,

$$
s=t_{2} \int_{w_{u}}^{+\infty} w n^{*}(w) d F(w)
$$

and $\tau=0$.

Note that the government budget constraints reduce the dimension of the policy space from five to two, since the tax rates $t_{1}$ and $t_{2}$ uniquely determine $\mathrm{s}, G$, and $\tau$.

The political process in this economy determines the tax rates used for redistributing income and for financing the apprehension t echnology. The voting rule we consider here is majority rule. Following Shepsle(1979), we assume that voting occurs on one tax rate at a time ${ }^{11}$ In particular, we assume that voting is sequential and tax rate $t_{1}$ is determined

10 To preserve the general equilibrium nature of the model, we assume that the consumption of apprehended criminals is financed through the lump-sum $\operatorname{tax} \tau$. While other specifications are possible, note that for the purpose of the quantitative analysis contained in the paper, the issue of how to finance $c_{\min }$ is fairly irrelevant, since the total consumption of apprehended criminals amounts to a very small fraction of the output in the economy.

${ }^{11}$ Introducing an institutional structure that reduces a multidimensional voting problem to a sequence of unidimensional problems eliminates the possibility of nonexistence of a voting equilibrium that is endemic to majority rule processes when the policy space is multidimensional (see e.g., McKelvey[1979]). 
before $t_{2}$ is voted on. ${ }^{12}$ When voters are faced with a choice between two alternatives, they vote for the tax rate that gives them higher utility, being fully aware of the consequences of their choice on the labor-leisure and worker-criminal decisions of all the agents in the economy and of the structure of the political process. A political-economic equilibrium for this economy is a competitive equilibrium where tax rates $t_{1}^{*}$ and $t_{2}^{*}$ are determined by majority rule according to the procedure described.

Given the sequential nature of the voting procedure, to characterize a politicaleconomic equilibrium we begin by characterizing the outcome of majority voting with respect to the share of income to be redistributed, for a given tax rate to finance the apprehension t echnology; Roberts (1977) shows that if the ordering of individual pre-t ax incomes is independent of which tax schedule is in operation, individual choice of a tax rate to finance redistribution via a linear tax schedule is inversely ordered by income. Meltzer and Richard (1981) extend Roberts' result to show that if pre-t ax income can be ordered by individual productivity regardless of the tax schedule that is implemented, then the outcome of majority rule is the tax rate most preferred by the voter with median productivit y. For any given $t_{1}$, our model satisfies Meltzer and Richard's condition. ${ }^{13}$ Hence, for any $t_{1} \in[0,1)$, we have that

$$
t_{2}^{*}\left(t_{1}\right)=\operatorname{argmax}_{\left\{t_{2}: t_{2} \in\left[0,1-t_{1}\right)\right\}} V\left(t_{1}, t_{2} ; w_{m}\right),
$$

where $w_{m}$ is the median productivity $\mathrm{y}$ in the population (which of course depends on $F$ ).

Using (20), for each agent $w$ we can determine their most preferred tax rate to finance the apprehension technology given the anticipated equilibrium outcome of the vote in the

12 It turns out that for the parameterizations of the model we consider here, the order of the two votes does not matter. Although this need not be true in general, we conjecture that this result follows from the uniqueness of the structure-induced equilibria (Shepsle [1979]) in these model economies.

${ }^{13}$ It follows immediately from (4) that for any $t_{1}$ and $t_{2}, y(w)$ is increasing in $\mathrm{w}$. 
second stage, which is given by

$$
t_{1}^{*}(w)=\operatorname{argmax}_{\left\{t_{1}: t_{1} \in\left[0,1-t_{2} *\left(t_{1}\right)\right)\right\}} V\left(t_{1}, t_{2}^{*}\left(t_{1}\right) ; w\right) .
$$

The outcome of the vote in the first stage, $t_{1}^{*}$, is the median of the distribution of $t_{1}^{*}(w)$ 's in the population. ${ }^{14}$ Given $t_{1}^{*}, t_{2}^{*}$ is uniquely determined.

\section{Data and Calibration}

To characterize the equilibria of our model and evaluate the effects of policy experiments, we need to rely on numerical techniques. In this section, we describe the data and the methods we use to select values for the structural parameters of our model. These parameters are the meari and the standard deviation of the distribution of log wages, $\bar{w}$ and $\sigma_{w}$, which characterize the heterogeneity of the agents in the model, the share of leisure in the utility function, $a$, the consumption level of an apprehended criminal, $c_{\min }$, the fraction of income criminals can steal from workers, $\alpha$, and the efficiency parameter of the apprehension technology, $\gamma$. Since our model is a static (one-year) model, we select 1990 as our base year and calibrate the model to the U.S. economy for that year.

\subsection{Population and Preferences}

Since our focus in this paper is on crimes that are motivated by the prospect of direct pecuniary gain, we restrict our attention to crimes against property. ${ }^{15}$ The categories of crime we include in our definition of property crime are burglary, larceny, motor vehicle theft, and robbery. ${ }^{16}$ The two main sources of information about these and other crimes in

${ }^{14}$ This follows from the fact that $V\left(t_{1}, t_{2}^{*}\left(t_{1}\right) ; w\right)$ is single-peaked for all $w$ 's. Note that the median of the distribution of the $t_{1}^{*}(w)$ 's is not necessarily the tax rate most preferred by the voter with median productivity.

${ }^{15}$ Although there may be financial gains associated with violent crimes, we do not attempt to model such crimes or the behavior that may lead to them. Moreover, property crimes accounted for about 90 percent of all crimes in the United States in 1990.

16 This definition of property crime differs from that used by the Federal Bureau of 
the United States are the annual Uniform Crime Reports (UCR) of the Federal Bureau of Investigation (FBI) and the annual National Crime Victimization Survey (NCVS) of the Bureau of J ustice Statistics (BJS). ${ }^{17}$ Two well-documented facts that emerge from these sources are that most property crimes occur in large cities and are committed by men. ${ }^{18}$ Based on these observations, we restrict our attention to a model economy populated only by men living in Metropolitan Statistical Areas (MSAs), who represent the population group most at risk of engaging in the type of criminal activities we focus on.

To estimate the distribution of wages faced by the agents in our model economy, we use data from the March Current Population Survey (CPS) of the Bureau of the Census for the survey year $1991 .{ }^{19}$ The size of the CPS sample for that year, consisting of men and women 16 years of age or older randomly selected from the U.S. population, is 119,165 . From this sample, we exclude all women and those men who are retired, in the military, in school, disabled, 65 years of age or older, or not living in an MSA. ${ }^{20}$ The restricted Investigation, which does not include robbery and does include arson. Our definition, however, is consistent with the definition used in most studies that try to isolate those crimes for which an individual is more likely to compare the relative pecuniary gains from legitimate and illegitimate activities. For definitions of the individual categories of crime included in our definition of property crime, see, e.g., U.S. Department of J ustice (1991).

17 The FBI has been accumulating statistics on crimes reported to state and local law enforcement agencies as well as the activities of these agencies since 1929. The NCVS started in 1973 and records self-reported information on victimizations for a national sample of about 50,000 households and 100,000 individuals every year. For a description of the differences between the UCR and the NCVS, see, e.g., DiIulio(1996). For the purpose of our study, note that the NCVS is generally regarded as a more reliable source of information about the incidence of property crimes than the UCR. The UCR, however, is the only data source available that contains information at the local and state level on both offenses and arrests for a wide variety of crimes.

${ }^{18}$ For instance, according to the UCR, in 1990 approximately 86 percent of all reported property crimes (according to our definition of propert y crimes) were recorded in Metropolitan Statistical Areas, and the fraction of people arrested for these crimes who were males was approximately 76 percent. On these points, see, e.g., Bearse (1996) and Glaeser and Sacerdote (1996).

${ }^{19}$ The data refer to the calendar year preceding the March survey.

${ }^{20}$ We also eliminate individuals who claim to be working but report no earnings, and 
sample we obtain, which we feel is representative of those individuals who are most likely to respond to the incentives we model in our theoretical framework, contains $30,472 \mathrm{men} .{ }^{21}$

For the men in our sample who report positive annual earnings, we define the log hourly wage as the natural logarithm of annual wage and salary earnings divided by the product of the weeks worked and usual weekly hours. Although most studies that examine the earnings of men do not account for those individuals who are unemployed (that is, do not correct for the sample select ion problem), it is necessary for our purposes to include both workers and non-workers, since we want to characterize the distribution of potential wages or productivities in our model economy. In fact, in our model we allow individuals the choice of whether to work, not work, or become a criminal, given the wages they face. Moreover, individuals with lower-than-average legitimate earning possibilities are more likely to commit crimes.

To correct for the presence of sample selection in the estimation of the mean and the standard deviation of the distribution of log hourly wages, we use a standard Heckman two-step procedure (Heckman[1979]). In the first step, we specify a probit equation for a dichotomous variable indicating whether an individual is employed or unemployed. We define someone to be employed if they worked more than 13 weeks in the year and unemployed if they worked less than that or not at all. ${ }^{22}$ The covariates we use in the probit equation are age, a race dummy equal to one if the individual is non-white and zero otherwise, and education. In the second step, we regress the log of the hourly wage of employed individuals on the inverse Mills ratio (obtained from the first step), age, a

individuals who report positive earnings but claim not to be working.

${ }^{21}$ Note that although 19 percent of the men arrested for property crimes in 1990 were under age 16 (only 0.7 percent were age 65 or older), data on wages necessitate that we restrict our attention to individuals who are 16 or older.

${ }^{22}$ With that restriction imposed, approximately 7.7 percent of the men in our sample are classified as unemployed. 
quadratic age term, a race dummy, and education. We use the mean and the standard deviation of the log of the selection-corrected hourly wages as our values for $\bar{w}$ and $\sigma_{w}$, respectively. The estimates we obtain for $\bar{w}$ and $\sigma_{w}$ are equal to 2.28 and 0.69 , respectively, which imply an average hourly wage of $\$ 12.40$ with a standard deviation of $\$ 9.70$.

With regard to the parameter a that represents the share of leisure in the utility function, we choose a value of 0.64 , which implies that about one-third of discretionary time is spent working. This number is consistent with many other calibration studies (see, e.g., Kydland and Prescott [1982]) as well as with the empirical literature on time use (see, e.g., J uster and Stafford [1991]).

\subsection{Technology}

To estimate the parameter $\gamma$ that measures the efficiency of the apprehension technology, we use equation (2) and state-level data for 1990 to specify the following statistical model:

$$
\ln \left(1-\pi_{a_{i}}\right)=-\gamma \ln \left(G_{i}\right)+\epsilon_{i}
$$

where $\pi_{a_{i}}$ denotes the apprehension probability y for property crimes in a given state (measured by the fraction of property crimes solved by arrests, or the clearance rate, in that state), $G_{i}$ denotes per capita expenditures on police protection in that state, and $\epsilon_{i}$ is an independently and identically normally distributed random term with zero mean and finite variance. ${ }^{23}$ Since the random term reflects the presence of measurement error as well as unobserved heterogeneity in the data, it may be correlated with police expenditures. For example, states may differ with respect to the attitude of their residents toward cooperating with the police or with respect to the propensity of their residents to engage in criminal

${ }^{23}$ Clearance rates by state are from U.S. Department of J ustice (1991), and per capita expenditures on police protection by state are from U.S. Department of J ustice (1992a). Note that, except for the presence of a random term, equation (22) is simply a logarithmic transformation of equation (2). 
activities or other exogenous factors that shift the apprehension probability of criminals. These factors are likely to affect the levels of expenditures for police protection that we observe across states. This implies that estimating $\gamma$ by ordinary least squares (OLS) would yield a biased estimate of this parameter. To overcome this problem, we estimate $\gamma$ using the method of instrumental variables. This estimation method requires finding one or more variables (i.e., the instruments) that are correlated with expenditures on police protection but not with the error term. One such variable is represented by the ranking of states in terms of their per capita levels of expenditures on police protection. ${ }^{24}$ The point estimate of $\gamma$ we obtain using this instrument is equal to 0.044 , and its 95 percent confidence interval is $[0.039,0.049] .{ }^{25}$

Another structural component of our model that we would like to identify from data is represented by the parameter $\alpha$ that characterizes criminal earnings from property crime as well as the costs of property crime to victims. Since serious data limitations make the estimation of this parameter using a single data source problematic, we try instead to combine various sources of information to obtain a range of sensible values for $\alpha$.

The 1989 Boston Youth Survey contains data on annual youth earnings from property crime in the Boston area in 1989. The 1980 NBER Survey of Inner City reports the same information for youths in Best on, Chicago, and Philadelphia in 1979. The average annual

${ }^{24}$ Note that identifying valid instruments at the local (i.e., city or MSA) level is more complicated, thus justifying our choice of states as units of observation.

25 Other possible instruments are per capita government expenditures net of expenditures on justice activities and public welfare (including or excluding expenditures on education) by state, the state ranking with respect to these expenditures, per capita disposable income by state, and the political party of the governor. Using these alternative instruments, we obtain point estimates of $\gamma$ that also lie in the interval $[0.039,0.049]$. As a term of comparison, note that the OLS estimate of $\gamma$ is equal to 0.047 . Moreover, given that aggregate per capita expenditures for police protection in 1990 amounted to $\$ 128$ and the aggregate clearance rate for property crimes that year was equal to 18.4 percent, a simple calculation using equation (2) yields a value for $\gamma$ of 0.042 . These results suggest that the simultaneity problem may not be severe in this case. 
earnings from property crime in 1990 dollars from these sources (obtained by deflating the nominal amounts reported in Freeman [1996] by the personal consumption expenditures deflator from the National Income and Product Accounts using 1990 as the base year) are $\$ 3,163$ for the Boston survey and $\$ 3,204$ for the NBER survey. Since in our model $\alpha$ represents the fraction of a worker's after-tax annual earnings that a criminal steals, we obtain the average deflated annual earnings of workers in the Boston metropolitan area for 1989 , equal to $\$ 28,302$ (in 1990 dollars); the weighted average of deflated annual earnings of workers in the Boston, Chicago, and Philadelphia metropolitan areas for 1979 , equal to $\$ 28,686$ (in 1990 dollars); and the effective marginal tax rates on labor for these two years, equal to 0.26 for 1989 and 0.27 for $1979 .{ }^{26}$ The two values of $\alpha$ we obtain by dividing average annual earnings from property crime by average after-tax annual earnings of a worker for the two years are fairly similar and are equal to 0.15 from the 1989 data and 0.16 from the data for 1979. A similar calculation using the average annual earnings from property crime estimated by Wilson and Abrahamse (1992) for the United States yields instead a value of $\alpha$ around $0.2 .^{27}$

In our model, we make the simplifying assumption that each criminal can victimize at most one worker, so that average criminal earnings equal the average cost of crime to a victim. In reality, it is certainly true that most criminals commit several crimes per year,

${ }^{26}$ Average annual earnings per worker are obtained from U.S. Department of Commerce $(1980,1991)$. Effective marginal tax rates on labor since 1947 are reported in McGrattan (1994).

${ }^{27}$ By combining the findings of the 1978 Rand Inmate Survey with the results of several other studies, Wilson and Abrahamse (1992) estimate average annual earnings from various crimes for different types of criminals. In particular, using their est imates (table 4, p. 366), we find that the average annual earnings from property crime of a typical burglar/thief in $1990^{\circ}$ dollars amount to $\$ 4,145$. Given that average annual earnings of a worker in the U.S. in 1990 were equal to $\$ 26,426$ (U.S. Department of Commerce [1995]) and that the effect ive marginal tax rate on labor for that year was 0.26 (McGratt an [1994]), annual criminal earnings of $\$ 4,145$ correspond to approximate ely 21 percent of a worker's after-tax annual earnings. 
and alt bough many property crimes involve more than one offender, the average annual earnings of a criminal may be larger than the average monetary loss suffered by a victim. Indeed, according to the UCR, in 1990 the average monetary loss per property crime in the United States was equal to $\$ 1,210$, which is smaller than the numbers reported above for criminal earnings. In reality, however, it is also true that the total cost of crime to a victim includes not only the value of the property taken during the commission of an offense, but also other forms of economic loss, such as medical expenses incurred because of injuries suffered during the commission of the offense, as well as intangible costs of fear, pain, and suffering. Hence, it is possible that once we take all forms of loss into consideration, the average cost of crime to a victim may be comparable-perhaps even larger-t han the average earnings of a criminal.

To assess the magnitude of at least some of the components of the cost of property crime to a victim, we use data from the NCVS for 1990. For the victims of robberies who sustained physical injuries (an event that occurred in 33 percent of the cases), the NCVS cent ains information regarding medical expenses and amount of pay lost because of injury. The average losses of these types reported are $\$ 1,493$ and $\$ 480$, respectively. Looking at the worst-case scenario, we estimate the average cost of property crime to a victim (given by the sum of the monetary loss and the other economic losses) as equal to $\$ 3,183$. A more conservative estimate of this cost, obtained by weighting medical expenses and pay losses by the probability y of sustaining an injury, is equal to $\$ 1,861$. Given that the average after-t ax annual earnings of a worker in the United States in 1990 amounted to $\$ 19,555$ (see U.S. Department of Commerce [1995], McGrattan [1994]), these estimates of the average cost of property crime to a victim imply values of $\alpha$ that range between 0.10 and 0.16.28 Based on all these considerations, we restrict our attention to values of $\alpha$

${ }^{28}$ Note that both of these estimates ignore psychological consequences of victimization 
between 0.1 and 0.2 .

The last component of our model that we need to estimate is the consumption level of an apprehended criminal, $c_{\min }$. To obtain a range of values for this parameter, we use data on expenditures for convicted felons in federal correctional facilities from the U.S. Bureau of Prisons, Office of Research and Evaluation (unpublished data, 1990). The per inmate annual expenditure on food (which we obtain by dividing total annual expenditures on food by the average daily population in federal correctional facilities for 1990) amounts to about $\$ 1,600$. If we include medical expenses, this number increases to about $\$ 3,600$.

Table 1: Calibration

\begin{tabular}{lcc}
\hline \hline & $\begin{array}{c}(1) \\
\text { Parameter } \\
\text { Range }\end{array}$ & $\begin{array}{c}(2) \\
\text { Benchmark } \\
\text { Economy }\end{array}$ \\
\hline $\bar{w}$ & 2.28 & 2.28 \\
$\sigma_{w}$ & 0.69 & 0.69 \\
$a$ & 0.64 & 0.64 \\
$\gamma$ & $0.039-0.049$ & 0.044 \\
$\alpha$ & $0.10-0.20$ & 0.15 \\
$c_{\min }$ & $\$ 1,600-\$ 3,600$ & $\$ 2,600$ \\
\hline \hline
\end{tabular}

Table 1 summarizes the values for the parameters of our model that we use to generate the results presented in the next section. To obtain a benchmark economy, we set the parameters $\gamma, \alpha$, and $c_{\min }$ equal to the midpoint of the range of their admissible values.

that may account for a substantial portion of the total cost of crime to victims. 


\section{Findings}

We begin this section by examining the properties of the competitive equilibria of our model economy. In particular, in section 4.1 , we analyze the changes in the crime rate in our benchmark economy as we vary the tax rates that are used to finance police expenditures and government subsidies. Also, we evaluate the impact of the distribution of wages and the efficiency of the police technology on the crime rate. In section 4.2 , we investigate the properties of the political-economic equilibrium for our benchmark economy and analyze the results of counterfactual experiments with respect to changes in the distribution of wages and the efficiency of the apprehension technology. We conclude, in section 4.3 , by examining the sensitivity, of our results to the choice of parameter values and the robustness of our findings with respect to alternative specifications of certain features of our theoretical model.

To provide terms of comparison for the numbers generated by our simulations, we present here a brief summary of relevant statistics for the U.S. economy in $1990 .^{29}$ In 1990, the individual victimization rate for completed personal Iarcenies and robberies in MSAs (defined as the number of victimizations per 100 individuals age 12 or older residing in MS AS) was equal to 7.1, and the household victimization rate for completed burglaries, household larcenies, and motor vehicle thefts in MSAs (defined as the number of victimizations per 100 households residing in MSAs) was equal to 14.8. Since the average number of persons age 12 or older per household residing in MSAs was equal to 2.1, combining the two victimization rates we find that the property crime rate in MSAs in 1990 (defined as the number of property crimes in 1990 per 100 individuals age 12 or older residing in MSAs) was equal to 14.2. The clearance rate for these crimes was equal to 18.4 percent.

\footnotetext{
29 The figures we report here are obtained from U.S. Department of J ustice (1991, 1992a,b) and U.S. Department of Commerce (1995).
} 
Other aggregate statistics for the United States in 1990 that are relevant for our analysis are as follows: GNP per capita was equal to $\$ 22,276$; total expenditures on police protection amounted to 0.6 percent of GNP, and social welfare expenditures net of expenditures on education and transfers to the elderly were equal to 7.8 percent of GNP.

\subsection{Competitive Equilibria}

Consider the model economy we obtain by setting the parameters $\bar{w}, \sigma_{w}, a, \gamma, \alpha$, and $c_{\min }$ equal to their values reported in column (2) of table 1. In addition, we assume that criminals who are not convicted of a crime cannot be excluded from receiving government subsidies (i.e., we set $\pi_{s}=1$ ). For this benchmark economy and three other model economies table 2 displays the crime rates that arise as we vary the tax rate used to finance expenditures on police protection, while keeping the tax rate that is used to finance government subsidies fixed at 7.8 percent. Consistently with the way it is measured in the data, we define the crime rate in a model economy as the number of crimes per 100 agents in the economy.

The experiments we conduct (the results of which are displayed in table 2) consist of comparing the crime rates in the benchmark economy with the crime rates that arise in other model economies that differ from the benchmark economy with respect to the mean of the distribution of log wages, its standard deviation, or the efficiency of the apprehension technology. In column (2), we consider an economy where the mean log hourly wage is increased from 2.28 to 2.37 , which corresponds to a 10 percent increase in the mean hourly wage rate from $\$ 12.40$ to $\$ 13.60 .^{30}$ The crime rate in this economy is lower than the crime rat e in the benchmark economy by from 3.7 to 5.1 percent, depending on the tax rate that is used to finance expenditures on police protection. This result is due to several factors.

\footnotetext{
${ }^{30}$ Notice that the coefficient of variation of the distribution of hourly wages is unchanged in this experiment.
} 
For any given $t_{1}$, the apprehension probability in this economy is higher because the higher level of income generates a higher level of revenues to finance the apprehension of criminals. Such an increase in the apprehension probability distorts an individual's decision against criminal activity. The increase in the apprehension probability, however, is only a part of the explanation. Notice that an increase in the average wage rate causes an increase in the returns to illegitimate activities by increasing the average earnings of the victims of crime. However, an increase in the average wage rate also results in an increase in the returns to market activities. As long as the conditions for a criminal who is apprehended are unchanged-that is, $c_{\min }$ remains the same-an increase in the average wage rate causes an increase in the opportunity cost of engaging in criminal activities, thus resulting in a decrease in the crime rate.

\section{Table 2: Effects of Police Expenditures on the Crime Rate}

\begin{tabular}{lcccc}
\hline \hline & $\begin{array}{c}(1) \\
\text { Benchmark } \\
\text { Economy }\end{array}$ & $\begin{array}{c}(2) \\
\text { Higher } \\
\text { Mean }\end{array}$ & $\begin{array}{c}(3) \\
\text { Higher } \\
\text { Variance }\end{array}$ & $\begin{array}{c}(4) \\
\text { Higher } \\
t_{1}\end{array}$ \\
\hline 0.002 & 10.7 & 10.3 & 12.0 & 10.4 \\
0.004 & 10.3 & 9.9 & 11.6 & 10.0 \\
0.006 & 10.0 & 9.6 & 11.4 & 9.7 \\
0.008 & 9.9 & 9.4 & 11.2 & 9.5 \\
0.010 & 9.8 & 9.3 & 11.1 & 9.4 \\
\hline \hline
\end{tabular}

Column (3) in table 2 displays crime rates in an economy where the mean of the distribution of log wages is the same as in the benchmark economy but the variance is higher. In particular, the standard deviation of log hourly wages is increased from 0.69 to 0.73 , which implies a 10 percent increase in the standard deviation of the wage rate 
from $\$ 9.70$ to $\$ 10.70 .^{31}$ More people become criminals in this economy (relative to the benchmark economy) because the returns from market-related activities relative to what criminals can steal is lower for more people. In fact, note that with a higher variance of wages we have a larger fraction of the population on both tails of the distribution. The increase in the crime rate that we observe relative to the benchmark economy varies between 12.2 and 13.3 percent, depending on the tax rate to finance the apprehension of criminals. The last column in table 2 shows the effects of increasing the efficiency of the apprehension technology. In particular, the economy we consider in that column differs from the benchmark economy with respect to the value of the parameter $\gamma$, which is increased from 0.044 to $0.049 .^{32}$ As one would expect, a more efficient technology for apprehending criminals induces the crime rate to fall for any level of expenditures used to operate this technology. As we vary $t_{1}$, we observe that the reduction in the crime rate relative to the benchmark economy varies between 2.8 and 4.1 percent.

In our model, there are two policy instruments that can be used to affect the crime rate: police protection and income redistribution. ${ }^{33}$ The results reported in table 2 indicate that, cet eris paribus, increasing the level of expendit ures on police protection reduces crime, although at a decreasing rate. Looking at column (1), for example, we see that as we increase $t_{1}$ from 0.2 percent to 0.4 percent, the crime rate in our benchmark economy decreases by 3.7 percent, while increasing $t_{1}$ from 0.8 percent to 1 percent induces a 1 percent reduction in the crime rate. In addition, table 2 shows that increased inequality

\footnotetext{
${ }^{31}$ Notice that this experiment implies a 7 percent increase in the coefficient of variation of the dist ribut ion of hourly wages.

${ }^{32}$ Given a per capita level of expenditures on police protection of $\$ 128$, which corresponds to the figure for the United States in 1990, such an increase in $\gamma$ implies a 10 percent increase in the apprehension probability.

${ }^{33}$ Although the severity of punishment, which in our model is captured by the parameter $c_{\min }$, could also be treated as a policy instrument, we do not model punishment explicitly and examine changes in $c_{\min }$ as part of our sensitivity y analysis.
} 
induces higher crime rates. This result suggests that income redistribution may also be a desirable instrument to reduce crime.

In table 3 , we analyze the effect of income redistribution on the crime rate in our benchmark economy. To evaluate the role oft he ability of government agencies to monitor the behavior of the recipients of transfer payments and discriminate among them based on their involvement in criminal activities, we specify five model economies that differ with respect to the value of $\pi_{s} \cdot{ }^{34}$ Table 3 displays the crime rates that arise in these economies as we vary the tax rate that is used to finance government subsidies, while keeping the tax rate that is used to finance expenditures on police protection fixed at 0.6 percent.

\section{Table 3: Effects of Income Redistribution on the Crime Rate}

\begin{tabular}{lccccc}
\hline \hline & $(1)$ & $(2)$ & $(3)$ & $(4)$ & $(5)$ \\
$t_{2}$ & $\pi_{s}=0$ & $\pi_{s}=0.25$ & $\pi_{s}=0.5$ & $\pi_{s}=0.75$ & $\pi_{s}=1$ \\
\hline 0.05 & 4.8 & 5.8 & 6.7 & 7.7 & 8.6 \\
0.10 & 2.3 & 4.1 & 6.3 & 8.8 & 11.1 \\
0.15 & 0 & 1.3 & 4.7 & 9.2 & 13.3 \\
0.20 & 0 & 0 & 0.9 & 8.7 & 15.4 \\
0.25 & 0 & 0 & 0 & 6.4 & 17.3 \\
0.30 & 0 & 0 & 0 & 0 & 19.2 \\
\hline \hline
\end{tabular}

We begin by imagining an economy where it is possible to exclude criminals from receiving subsidies from the government. Crime rates for the economy where zero percent of the criminals receive the subsidy (i.e., $\pi_{s}=0$ ) are displayed in column (1). As one would

34 Recall that $\pi_{s}$ measures the probability that criminals who are not caught committing a crime receive government subsidies. Note that none of the qualitative features of our model economies illustrated in table 2 depends on the value of $\pi_{s}$. 
expect, the crime rat e decreases as we increase the level of subsidies in this economy. This result is mainly due to the overwhelming increase in the opportunity cost of engaging in criminal activities as the level of subsidies increases. It is important to stress that in this economy the government can distinguish among the recipients of transfer payments, so that criminals can be excluded from them. For this economy, a zero crime rate is achieved with a 15 percent tax rate.

Notice how these results change as we gradually increase the possibility of criminals receiving government subsidies. For example, the economy where 50 percent of the criminals are able to receive subsidies is displayed in column (3). In this economy, the crime rate still decreases as sụbsidies increase, although at a lower rate, and it is possible to achieve crime rates close to zero with tax rates around 20 percent. The last column of table 3 displays an economy where it is not possible to distinguish between criminals and non-criminals as recipients of transfer payments, so 100 percent of the criminals who are not caught committing a crime are able to receive government subsidies (i. e., $\pi_{s}=1$ ). In this economy, subsidies do not necessarily represent an opportunity cost of criminal activities, since criminals receive them as long as they are not caught. The behavior of the crime rate with respect to changes in the level of subsidies is significantly different in this economy compared to the economy displayed in column (1). Here, the crime rate increases as we increase the level of subsidies. Some of this behavior is also visible for the case where 75 percent of the criminals are able to receive the subsidy (column (4)).

There are several reasons this pattern arises. Given that subsidies no longer represent a substantial opportunity cost for criminals, the distortionary effects of increases in the tax rate to finance higher subsidies start playing an important role. Increases in tax rates decrease the returns from legitimate activities, causing a reduction in the number of hours 
worked as well as the number of people working in legitimate market activities. This in turn lowers output in the economy, and given the constant tax rates used to finance police expenditures, it lowers the total resources devoted to the apprehension of criminals. Such a decrease in revenues for police expenditures results in a reduction of the apprehension probability, further decreasing the opportunity cost of engaging in criminal activities.

Some of the results we see in tables 2 and 3 are worth repeating. We find that for given levels of government subsidies and police expenditures, an economy with a more equal distribution of wages has an equilibrium crime rate that is lower than the equilibrium crime rate in an economy with a more unequal distribution of wages. However, we also find that in an economy where it is not possible to distinguish among the recipients of transfer payments, reducing the inequality in incomes through government subsidies does not necessarily lower the crime rate. In fact, we find higher subsidies resulting in higher crime rates in such economies. ${ }^{35}$

\subsection{Political-Economic Equilibria}

We begin this section by considering the level of income redistribution induced by majority voting in our benchmark economy when we abstract from criminal behavior. In particular, suppose that individuals are not given the option of engaging in criminal activities and simply decide how much to work if they choose to work at all. In this case,

${ }^{35}$ On this point, recall that the two major social experiments (the LIFE experiment and the TARP ) that were implemented in the United States to assess the effect of subsidies to ex-prisoners on their recidivism generated conflicting evidence (see footnote 4 ). In particular, while the LIFE experiment indicated that subsidies were effective at reducing the involvement in criminal activities of the people who received them, the results of the TARP supported the opposite conclusion. For the purpose of our analysis, it is interesting to note that Rossi, Berk, and Lenihan $(1980$, p. 43) questioned the validity of the results of the LIFE experiment on the grounds that "the findings had been obtained in an experiment administered by an energetic and dedicated research team. A program that was administered by even the best of federal or state agencies could hardly command the same level of effort on the part of program personnel." 
the level of subsidies chosen under majority rule would be determined only by the desire of the median voter (i.e., the individual with median productivity) to realist ribute income. ${ }^{36}$ In fact, given that the distribution of hourly wages in our benchmark economy is such that the median wage is significantly bel ow the mean wage ( $\$ 9.80$ and $\$ 12.40$, respectively), we would expect majority voting to induce a relatively high level of redistribution. Indeed, such a case is displayed in column (1) of table 4 , where majority voting gives rise to a 27 percent tax rate to finance government subsidies.

\section{Table 4: Political-Economic Equilibria with and without Criminal Behavior}

\begin{tabular}{lccc}
\hline \hline & $\begin{array}{c}(1) \\
\text { No Criminal } \\
\text { Behavior }\end{array}$ & $\begin{array}{c}(2) \\
\text { No Criminals Can } \\
\text { Receive Subsidies }\end{array}$ & $\begin{array}{c}(3) \\
\text { All Criminals Can } \\
\text { Receive Subsidies }\end{array}$ \\
\hline$t_{1}^{*}$ & - & 0 & 0.004 \\
$t_{2}^{*}$ & 0.27 & 0.27 & 0.17 \\
Crime Rate & - & 0 & 14.6 \\
\hline \hline
\end{tabular}

One question we want to address is whether allowing for the possibility of criminal behavior significantly changes the amount of redistribution induced by majority voting. The answer depends heavily on the way subsidies affect the crime rate. In section 4.1, we showed that the impact of subsidies on the crime rate crucially depends on whether non-apprehended criminals are able to receive government subsidies. Column (2) of table 4 displays the tax rates in the political-economic equilibrium (PEE) for an economy where none of the criminals receive government subsidies. The political process in this case still induces a 27 percent tax rate to finance subsidies and a zero tax rate to finance the ${ }^{36}$ See, e.g., Meltzer and Richard (1981). 
apprehension of criminals. In this environment, it is possible to achieve a zero crime rate with only the use of subsidies, and the crime rate in the PEE is zero. Thus, society is able to achieve the same level of redistribution and a zero level of criminal activity as in an economy where agents are not allowed to engage in illegitimate activities.

The last column of table 4 displays the tax rates in the PEE for an economy where non- apprehended criminals cannot be excluded from receiving government subsidies. In such a case, we know from earlier results that increases in the level of subsidies may increase the crime rate. In this environment, the outcome of majority voting is a significantly lower amount of redistribution. In fact, the equilibrium tax rate to finance government subsidies is 17 percent, and the equilibrium tax rate to finance expenditures on police protection is 0.4 percent. The corresponding equilibrium crime rate for this economy is 14.6. The possibility that higher subsidies encourage rather than discourage participation in illegitimate activities imposes an additional constraint on society's choice of an income redistribution policy, over and above the one generated by the disincentive effects of taxation on the individuals' labor-leisure choice. Thus, the political process induces a lower level of redistribution than in the economy displayed in column (2), a positive level of expenditures on police protection, and a positive crime rate. ${ }^{37}$

Since we believe that in reality the government cannot discriminate between criminals who are not convicted of a crime and non-criminals, for the remainder of the paper we focus on the case where the government cannot prevent criminals from receiving subsidies unless they are convict ed of a crime (i.e., $\pi_{s}=1$ ). In table 5 , we investigate the effects of exogenous changes in the distribution of wages and in the efficiency of the apprehension

\footnotetext{
37 Note that in the economy where all the criminals can receive subsidies, it is still technologically feasible to achieve a zero crime rate for various combinations of subsidy and police expenditures. These policy options, however, turn out not to be politically feasible.
} 
technology on the PEE.In particular, the experiments we consider here are the same experiments we considered in table 2.

Column (1) in table 5 displays the tax rates, the crime rate, the apprehension probability, and the per capita income in the PEE of our benchmark economy. Notice that with the exception of the level of transfers as a percentage of GNP, these numbers are fairly close to the figures relative to the U.S. economy in 1990 summarized at the beginning of section 4. Although our model is stylized, this result confirms its ability to mimic some important features of the aggregate phenomena we are interested in studying.

\section{Table 5: Political-Economic Equilibria}

\begin{tabular}{lcccc}
\hline \hline & $\begin{array}{c}(1) \\
\text { Benchmark } \\
\text { Economy }\end{array}$ & $\begin{array}{c}(2) \\
\text { Higher } \\
\text { Mean }\end{array}$ & $\begin{array}{c}(3) \\
\text { Higher } \\
\text { Variance }\end{array}$ & $\begin{array}{c}(4) \\
\text { Higher } \\
\text { Efficiency }\end{array}$ \\
\hline$t_{1}^{*}$ & 0.004 & 0.005 & 0.005 & 0.005 \\
$t_{2}^{*}$ & 0.17 & 0.19 & 0.20 & 0.20 \\
Crime Rate & 14.6 & 14.5 & 17.0 & 14.6 \\
Apprehension Probability & 0.18 & 0.19 & 0.19 & 0.21 \\
Per Capita Income & 22,276 & 24,040 & 22,185 & 21,738 \\
\hline \hline
\end{tabular}

Column (2) in table 5 lists the properties of the PEE in an economy that differs from the benchmark economy only with respect to the mean of the wage distribution. In this economy, the mean of log hourly wages is set equal to 2.37 instead of 2.28 as in the benchmark economy. By comparing column (2) to column (1), we see that the political process in this economy determines higher tax rates to finance both government subsidies and police expenditures. The apprehension probability and per capita income are also 
higher and the crime rate is lower. To interpret these results, recall that in section 4.1 we have shown that for each combination of tax rates, a higher mean wage induces a lower crime rate. This implies that society can achieve a higher level of redistribution at the same cost in terms of the induced crime rate. Since the economy is richer, however, agents are also willing to spend more money to finance the apprehension of criminals, which in turn increases the apprehension probability and reduces crime.

Column (3) in table 5 refers to the PEE of an economy that differs from the benchmark economy only with respect to the variance of the distribution of log wages. In particular, the standard deviation of log wages in this economy has been increased to 0.73 from its benchmark value of 0.69 . Again, majority voting in this economy yields tax rates to finance government subsidies and police expenditures that are both higher than the corresponding tax rates in the PEE for the benchmark economy. The apprehension probability is also higher, and so is the resulting crime rate. Per capita income is, however, lower compared to the benchmark economy. The intuition for these results derives primarily from the fact that an increase in the variance of log wages decreases the ratio of the median to the mean wage. This in turn increases the desired level of realist ribution by the voters whose wages are below the mean wage and makes them willing to tolerate a higher level of crime in order to achieve more redistribution. Since the crime rate is higher, however, agents are also willing to spend more money to finance the apprehension of criminals, which increases the apprehension probability and contains the overall increase in the crime rate.

The last column in table 5 lists the properties of the PEE in an economy where the apprehension technology is more efficient than in the benchmark economy ( $\gamma$ is set equal to 0.049 instead of 0.044 ). Again, majority voting in this economy generates higher tax rates than in the benchmark economy and a higher apprehension probability. The crime 
rate is, however, unchanged, and per capita income is lower. Since the distribution of wages is unchanged in this economy, these results simply arise from the fact that a more efficient apprehension technology allows the political process to achieve a higher level of redistribution at the same cost in terms of the crime rate it induces. The disincentive effects of the higher taxes required to finance the higher subsidies, however, induce per capita income to fall.

Another interesting result that emerges from table 5 is that in a political-economic equilibrium, higher subsidies are not necessarily associated with higher crime rates. In fact, an economy with a more generous welfare system may have a lower, a higher, or even the same crime rate as an eçonomy with a less generous welfare system. This result implies that a serious empirical investigation of the relationship between income redistribution and crime using either cross-section or time-series data would have to carefully control for structural differences among economies that simultaneously affect their choice of an income redistribution policy and their equilibrium crime rate.

\subsection{Sensitivity Analysis}

In tables 3 and 5, we have analyzed the effects of changes in the distribution of wages and the efficiency of the police technology on the competitive and the political-economic equilibria of our model economies, respectively. In this section, we discuss the sensitivity of our results to our choice of values for the other parameters of our model (i.e., the share of leisure in the utility function, $a$, the fraction of a worker's after-tax income a criminal can steal, $\alpha$, and the consumption level of an apprehended criminal, $\left.c_{\min }\right)$.

To begin, notice that none of the qualitative results presented in sections 4.1 and 4.2 depends on the specific parameter values we have chosen to characterize our benchmark economy. Furthermore, although for different reasons, a decrease in $a, \alpha$, or $c_{\text {min }}$ produces 
the same qualitative effect on the crime rate in a competitive equilibrium. Decreasing the share of leisure in the utility function induces people to work more. This makes an economy richer and induces a lower crime rate. A decrease in either $c_{\min }$ or $\alpha$ also lowers the crime rate by lowering the expected returns to crime. Because of these similarities, we restrict our attention to one of these parameters and illustrate the quantitative effects of a change in $c_{\min }$ on the political-economic equilibrium.

The experiment we consider consists of lowering $c_{\min }$ by 10 percent (from $\$ 2,600$ to $\$ 2,340$ ), while leaving the other parameters fixed at their benchmark values. With respect to what we observed in our benchmark economy (table 5, column (1)), the lower $c_{\min }$ induces higher equilibrium tax rates to finance both police expenditures and income redistribution (equal to 0.005 and 0.19 , respectively) and a 1.4 percent reduction in the equilibrium crime rat e (equal to 14.4). As one would expect, making apprehended criminals worse off reduces the incentives to engage in criminal activities, and the diminished threat of crime induces society to vote for a higher level of redistribution. Lower values of a and $\alpha$ produce results that go in the same directions.

To conclude this section, we briefly discuss alternative specifications for two of the features of our model economy and comment on their implications for our results. The first modeling choice we consider is the specification of the physical environment in which workers and criminals interact. In the model described in section 2, we have assumed that the probability of a criminal hitting a victim is equal to the fraction of workers in the economy. Alternatively, we could assume that, as long as the fraction of workers in the economy is larger than the fraction of criminals, a criminal hits a victim with probability one. Since the calibration of the parameters of our model is independent of the structure of the physical environment of our model economy, we can analyze the consequences of this 
alternative specification in the context of our benchmark economy. Notice that eliminating the possibility that criminals may be unsuccessful in finding a victim results in an increase of the crime rate for any combination of taxes. While none of the qualitative results described above is affected, the increase in the victimization probability for a worker (which is now equal to the ratio of the fraction of workers in the economy to the fraction of criminals) dramatically reduces the political-economic equilibrium level of transfers in our benchmark economy, from 17 to 7 percent of GNP. The equilibrium expenditure level on police protection, however, increases from 0.4 to 0.5 percent of GNP, and the equilibrium crime rate is also higher (17.0).

To generate the results presented in sections 4.1 and 4.2, we have assumed that in the event a criminal is apprehended, his victim does not incur any loss. In reality, however, stolen cash and property are rarely recovered, and even when they are, the victims may still incur the other forms of loss related to their victimization that we discussed in section 3. If we assume that a worker who is victimized loses a fraction $\alpha$ of his after-tax income regardless of whether the criminal is apprehended, while maintaining the assumption that the consumption of an apprehended criminal is equal to the subsistence level $c_{\min }$, we obtain the following results. ${ }^{38}$ The crime rates in the competitive equilibria of our benchmark economy remain essentially the same. The consequences of a given crime rate for the victims, however, worsen, and the usefulness of police deteriorates. As a consequence, the level of transfers in the political-economic equilibrium for our benchmark economy decreases from 17 to 14 percent of GNP, and so do the level of expenditures on police protection (from 0.4 to 0.3 percent of GNP) and the crime rate (from 14.6 to 13.4 ). All the qualitative results presented above, however, continue to hold.

\footnotetext{
${ }^{38} \mathrm{~F}$ or simplicity, we are assuming here that in the event a criminal is convicted of a crime, his loot is wasted.
} 


\section{Concluding Remarks}

In this paper, we have constructed a general equilibrium model to provide a controlled environment for assessing the relative efficacy and desirability of alternative crime-control policies and conducting counterfactual experiments. We have treated the distribution of wages and the police t ethnology as exogenous and have analyzed the way in which the crime rate and the levels of expenditures for police protection and income redistribution are simultaneously determined in a political-economic equilibrium.

Our model is very simple and ignores dynamic issues related to recidivism, life-cycle effects, stigma, and other long-term consequences of conviction. By treating the level of punishment as exogenoụs, we also ignore many interesting issues related to punishment. The general equilibrium nature of our framework, however, brings in important issues that were not fully analyzed by the previous literature. For example, we show that in an environment where it is impossible to distinguish between criminals and non-criminals as recipients of transfer payments, increasing government subsidies may increase the crime rate because of the distortionary effects of the higher taxes that are necessary to finance the subsidy increase. This in turn affects the level of subsidies in a political-economic equilibrium. 


\section{References}

Aiyagari, S. R., and D. Peled. "Social Insurance and Taxation under Sequential Majority Voting and Utilitarian Regimes." J ournal of Economic Dynamics and Control. Volume 19,1995,pp.1511-1528.

Bearse, P. M. "Community Formation and Youth Crime." Mimeo. 1996.

Becker, G. S. "Crime and Punishment: An Economic Approach." J ournal of Political Economy. Volume 78, 1968, pp.169-217.

Benoit, J. P., and M.J. Osborne. "Crime, Punishment, and Social Expenditure." J ournal of Institutional and Theoretical Economics. Volume 151,1995, pp.326-347.

DiIulio, J. J. "Help Wanted:Economists, Crime, and Public Policy." J ournal of Economic Perspectives. Volume 10,1996, pp. 3-24.

Ehrlich, I. "Participation in Illegitimate Activities: A Theoretical and Empirical Investigation." J ournal of Political Economy. Volume 81,1973, pp.521-565.

Ehrlich, I. "On the Usefulness of Controlling Individuals: An Economic Analysis of Rehabilitation, Incapacitation, and Deterrence." American Economic Review. Volume 71, 1981, pp. 307-322.

Ehrlich, I. "Crime, Punishment, and the Market for Offenses." J ournal of Economic Perspectives. Volume 10,1996, pp. 43-67.

Freeman, R. B. "Crime and Unemployment ." In Wilson J.Q., ed.Crime and Public Policy. San Francisco: ICS Press, 1983.

Freeman, R. B. "Why Do So Many American Young Men Commit Crimes and What Might We Do about It?" J ournal of Economic Perspectives. Volume 10,1996,pp. $25-42$.

Furlong, W. J. "A General Equilibrium Model of Crime Commission and Prevention." J ournal of Public Economics. Volume 34,1987, pp. 87-103.

Glaeser, E. L., and B. Sacerdote. "Why Is There More Crime in Cities?" Mimeo, 1996.

Harris, J.R. "On the Economics of Law and Order." J ournal of Political Economy. Volume 78, 1970, pp. 165-174.

Heckman, J. "Sample Selection Bias as a Specification Error." Econometrica. Volume 47, 1979, pp. 153-161.

Hellwig, M. F. "The Optimal Linear Income Tax Revisited." J ournal of Public Economics. Volume 31,1986, pp.163-179.

Jușter, F. T., and F.P.Stafford. "The Allocation of Time: Empirical Findings, Behavioral Models, and Problems of Measurement." J ournal of Economic Literature. Volume 29,1991, pp. 471-522.

Kydland, F. E., and E. C. Prescott. "Time to Build and Aggregate Fluctuations." Econometrica. Volume 50,1982, pp.1345-1370. 
McGrattan, E. R. "The Macroeconomic Effects of Distortionary Taxation." J ournal of Monetary Economics. Volume 33, 1994, pp. 573-601.

McKelvey, R. "General Conditions for Global Intransitivities in Formal Voting Models." Econometrica. Volume 47,1979, pp. 1085-1112.

Meltzer, A. H., and S.F. Richard. "A Rational Theory of the Size of the Government ." J ournal of Political Economy. Volume 89,1981, pp.914-927.

Mirrlees, J. A. "Optimal Tax Theory: A Synthesis." J ournal of Public Economics. Volume 6,1976, pp. 327-358.

Polinsky, A.M., and S. Shavell. "The Optimal Use of Fines and Punishment ." J ournal of Public Economics. Volume 24,1984, pp.89-99.

Pyle, D. J. The Economics of Crime and Law Enforcement. New York: St. Martin Press, 1983.

Roberts, K. "Voting over Income Tax Schedules." Journal of Public Economics. Volume 8,1977 , pp. 329-340.

Romer, T. "Individual Welfare, Majority Voting, and the Properties of a Linear Income Tax." J ournal of Public Economics. Volume 4,1975,pp.163-185.

Rossi, P. H., Berk, R. A., and K. Lenihan. Money, Work, and Crime. New York: Academic Press, 1980.

Sala-i-Martin, X."Public Welfare and Growth." Economic Growth Center, Yale Universit y. Working Paper No.666,1992.

Shepsle, K. A. "Institutional Arrangements and Equilibrium in Multidimensional Voting Models." American J ournal of Political Science. Volume 23,1979, pp. 27-59.

Sheshinski, E. "The Optimal Linear Income Tax." Review of Economic Studies. Volume 39,1972 , pp. 297-302.

Stern, N.H. "On the Specification of Models of Optimum Income Taxation." J ournal of Public Economics. Volume 6,1976, pp.123-162.

Stigler, G. J. "The Optimum Enforcement of Laws." J ournal of Political Economy. Volume 78,1970,pp. 526-536.

Tauchen, H., Witte, A. D., and H. Griesinger. "Criminal Deterrence: Revisiting the Issue with a a Birth Cohort." Review of Economics and Statistics. Volume 76,1994, pp. 399-412.

U.S. Department of Commerce, Bureau of the Census. State and Metropolitan Area Data Book,1980 and 1991.

U.S. Department of Commerce, Bureau of the Census. Statistical Abstract of the United States, 1995.

U.S. Department of Justice, Federal Bureau of Investigation. Crime in the United States, 1990, 1991. 
U.S. Department of Justice, Bureau of J ustice Statistics. Justice Expenditure and Employment, 1990. Bulletin NCJ-135777,1992a.

U.S. Department of Justice, Bureau of J ustice Statistics. Criminal Victimization in the United States,1990. Report NCJ-134126,1992b.

Wilson, J. Q., and A. Abrahamse. "Does Crime Pay?" Justice Quarterly. Volume 9, 1992, pp. 359-377.

Witte, A.D. "Estimating the Economic Model of Crime with Individual Data." Quarterly J ournal of Economics. Volume 94,1980, pp. 57-84.

Wolpin, K. "An Economic Analysis of Crime and Punishment in England and Wales, 1894-1967." J ournal of Political Economy. Volume 86,1978, pp. 815-840. 